\title{
PERIOD BETWEEN OVULATION AND BIRTH
}

\author{
BY \\ J. R. GIBSON and T. DOUGRAY \\ From the Department of Social Medicine, University of Birmingham, and St. Chad's Hospital, Birmingham
}

Because dates of coitus, ovulation, and fertilization are usually unknown, examination of the duration of gestation in a large series of women is necessarily based on the period of amenorrhoea from onset of menstruation to birth. The considerable variation in this period is due partly to variation in the interval between onset of menstruation and ovulation, and partly to variation in the time between ovulation and birth. In this communication we examine the period between ovulation and birth, which has been estimated for each of 763 women by:

(a) using information about mean length of cycle to estimate the interval between onset of menstruation and ovulation,

(b) subtracting this interval from the period of amenorrhoea.

\section{Material aNd Methods}

The period of amenorrhoea (from onset of menstruation to birth) and a menstrual history during the year after birth, were recorded for all mothers domiciled in the County Borough of Smethwick whose children were born between April 1, 1949, and March 31, 1950. To exclude some pregnancies of abnormal duration, the examination which follows is restricted to 1,227 mothers of single births which survived at least until the end of the first year.

Period of Amenorrhoea.-Date of onset of the last menstrual period preceding pregnancy was obtained if it was known at the first ante-natal attendance, and date of birth was later extracted from the records of notification of birth submitted to the public health department. For 108 of the 1,227 mothers the period of amenorrhoea was unknown.

Mean Length of Cycle.-Either on leaving hospital, or at the first home visit by a health visitor, mothers were given a calendar on which they were asked to cross off each day of bleeding during the year after the birth of the child. This calendar was printed on a child's record card on which were entered other items of more interest to the mother, such as the weight of the child. Mothers were subsequently interviewed at a Welfare Centre or at home within 2 weeks of each quarter during the year following birth, when the menstrual history was copied on to another document. These documents provided the data used in the analysis which follows.
In another report (McKeown, Gibson, and Dougray 1953) based on the same data, mean length of cycle was estimated in women for whom at least three cycles were recorded in the year after birth by

(a) Excluding women whose cycles were judged on inspection to be irregular,

(b) Excluding from the- remaining histories occasional cycles whose lengths were inconsistent with the other observations.

Some such procedure is necessary if mean length of cycle is to be given for individual women. For the present purpose we have used a different system of exclusion, which, although more cumbersome and probably not more accurate, has the merit of being objective. The procedure is as follows:

(a) Exclusion of 351 women (of 1,119 of known period of amenorrhoea) for whom fewer than five cycles were recorded.

(b) Omission of cycles of less than 16 or more than $48 \mathrm{\omega}$ days from records of the 768 women with at leas. five recorded cycles.

(c) Estimation for each woman of crude mean lengt of the remaining cycles.

(d) Omission of cycles more than seven days above or below the crude mean.

(e) Exclusion of the five women who had fewer than three cycles (after $(a)-(d))$.

$(f)$ Estimation of mean length of the remaining cycles for each of 763 women.

It should perhaps be made clear that this somewhat elaborate procedure is not intended to give means which can be regarded as representative of a group of parous women; it is merely designed to give means in that selected group of women whose cycles are sufficiently regular to make estimates of their mean length of any value.

\section{Period Between Ovulation and Birth}

(a) VARIABILITY.-There is a good deal of evidence which suggests that the length of the post-ovulatory phase is fairly constant, being about 14 days, and that variation in length of cycle is mainly due to variation in the pre-ovulatory phase. The interval between onset of menstruation and ovulation has therefore been estimated for each of 763 women by subtracting 14 days from the mean length of cycle, and the period between ovulation and birth was obtained by subtracting the interval between onset 
of menstruation and ovulation from the period of amenorrhoea.

Table I compares the distributions of the period between ovulation and birth estimated for 763 pregnancies, and the period of amenorrhoea recorded for 1,119 pregnancies (before exclusion of cases referred to above): the means (in days) are 265.6 and 280.5 respectively. The most obvious result of removing variation attributable to the interval between menstruation and ovulation is an increase (from 25.8 to 31.7 per cent.) in the proportion of cases delivered in what corresponds to the 41 st week of amenorrhoea. But there is still considerable variation in the period between ovulation and birth(Figure).

TABLE I

PERIOD BETWEEN OVULATION AND BIRTH

\begin{tabular}{|c|c|c|c|c|c|}
\hline $\begin{array}{c}\text { Period of } \\
\text { Amenorrhoea } \\
\text { (days) }\end{array}$ & $\begin{array}{c}\text { Number } \\
\text { of } \\
\text { Cases }\end{array}$ & $\begin{array}{c}\text { Per } \\
\text { cent. }\end{array}$ & $\begin{array}{c}\text { Estimated* } \\
\text { Period from } \\
\text { Ovulation } \\
\text { to Birth } \\
\text { (days) }\end{array}$ & $\begin{array}{c}\text { Number } \\
\text { of } \\
\text { Cases }\end{array}$ & $\begin{array}{c}\text { Per } \\
\text { cent. }\end{array}$ \\
\hline $\begin{array}{l}217-223 \\
224-230 \\
231-237 \\
238-244 \\
245-251 \\
252-258 \\
259-265 \\
266-272 \\
273-279 \\
280-286 \\
287-293 \\
294-300 \\
301-307 \\
308-314 \\
315-321 \\
322 \text { and } \\
\text { over }\end{array}$ & $\begin{array}{r}3 \\
3 \\
7 \\
8 \\
18 \\
28 \\
45 \\
124 \\
225 \\
289 \\
248 \\
84 \\
21 \\
8 \\
4 \\
4\end{array}$ & $\begin{array}{r}0.26 \\
0.26 \\
0.62 \\
0.71 \\
1 \cdot 61 \\
2 \cdot 50 \\
4.02 \\
11.08 \\
20 \cdot 11 \\
25 \cdot 82 \\
22 \cdot 16 \\
7.51 \\
1 \cdot 88 \\
0.71 \\
0.36 \\
0.36\end{array}$ & $\begin{array}{l}203-209 \\
210-216 \\
217-223 \\
224-230 \\
231-237 \\
238-244 \\
245-251 \\
252-258 \\
259-265 \\
266-272 \\
273-279 \\
280-286 \\
287-293 \\
294-300 \\
301-307 \\
308-314\end{array}$ & $\begin{array}{r}2 \\
2 \\
3 \\
9 \\
10 \\
13 \\
43 \\
89 \\
148 \\
242 \\
134 \\
48 \\
11 \\
5 \\
2 \\
2\end{array}$ & $\begin{array}{r}0.26 \\
0.26 \\
0.39 \\
1.18 \\
1.31 \\
1.70 \\
5.63 \\
11.66 \\
19.40 \\
31.72 \\
17.56 \\
6.29 \\
1.44 \\
0.66 \\
0.26 \\
0.26\end{array}$ \\
\hline $\begin{array}{l}\text { Numbers } \\
\text { Mean } \\
\text { Error of } \\
\text { Mean } \\
\text { Standard } \\
\text { Deviation }\end{array}$ & $\begin{array}{c}1,119 \\
280 \cdot 5 \\
0.40 \\
13.5 \\
\pm 0.3\end{array}$ & $\begin{array}{l}\frac{100}{-} \\
-\end{array}$ & 二 & $\begin{array}{c}763 \\
265.6 \\
0.46 \\
12.8 \\
\pm 0.3\end{array}$ & $\begin{array}{l}100 \\
- \\
-\end{array}$ \\
\hline
\end{tabular}

*Method of estimation described in text.

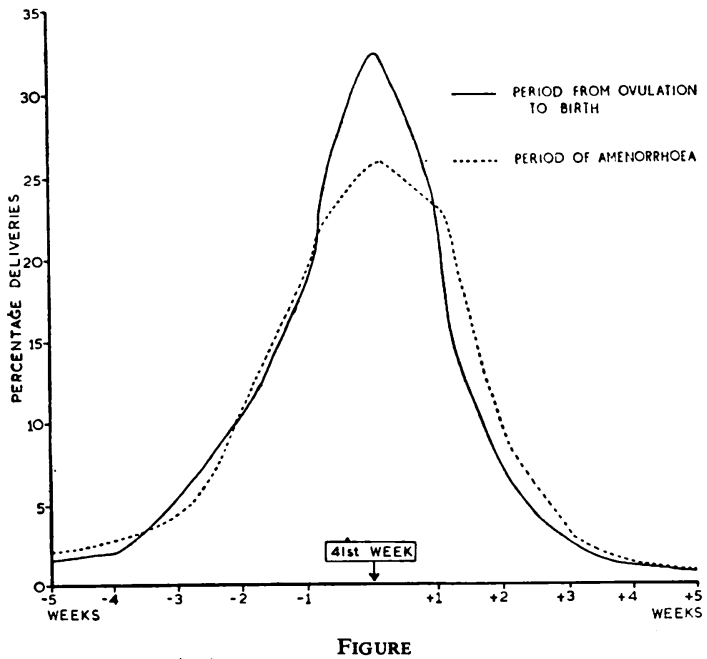

(b) Relation to Maternal Age and Birth Order. -It has been shown that there are slight negative correlations between period of amenorrhoea and maternal age, and between period of amenorrhoea and parity (Karn and Penrose, 1951). It is possible, however, that these correlations are due to association of the interval between onset of menstruation and ovulation with age and parity. Indeed Gunn, Jenkin, and Gunn (1937) reported that the length of the menstrual cycle decreased with age, and it seems reasonable to suppose that it is the preovulatory phase which is mainly affected. So far as we are aware the association between length of cycle and parity has not been examined.

The relation of the mean period between ovulation and birth to parity and to maternal age is shown in Tables II and III respectively; there is no consistent

TABLE II

MEAN PERIOD FROM OVULATION TO BIRTH RELATED TO PARITY

\begin{tabular}{|c|c|c|c|c|c|c|c|}
\hline Parity & .. & .. & .. & 1 & 2 & 3 & 4 \\
\hline Number of Pregnancies & $\ldots$ & $\ldots$ & $\ldots$ & 312 & 239 & 113 & 99 \\
\hline Mean Period (days) & . & . & . & $265 \cdot 9 \pm 0 \cdot 71$ & $265 \cdot 2 \pm 0 \cdot 77$ & $264 \cdot 0 \pm 1 \cdot 43$ & $267 \cdot 4 \pm 1 \cdot 23$ \\
\hline Standard Deviation & $\ldots$ & $\ldots$ & $\ldots$ & $12 \cdot 60$ & $11 \cdot 92$ & $15 \cdot 25$ & $12 \cdot 21$ \\
\hline
\end{tabular}

TABLE III

MEAN PERIOD FROM OVULATION TO BIRTH RELATED TO MATERNAL AGE

\begin{tabular}{|c|c|c|c|c|c|c|c|}
\hline Maternal Age (years) & $\cdots$ & . & $\cdots$ & 24 and under & $25-29$ & $30-34$ & 35 and over \\
\hline Number of Pregnanciest & $\cdots$ & . & $\cdots$ & 230 & 267 & 168 & 97 \\
\hline Mean Period (days) & $\cdots$ & $\cdots$ & . & $265 \cdot 5 \pm 0 \cdot 79$ & $265 \cdot 4 \pm 0 \cdot 84$ & $266 \cdot 2 \pm 0 \cdot 92$ & $265 \cdot 2 \pm 1 \cdot 38$ \\
\hline Standard Deviation & $\ldots$ & $\ldots$ & $\ldots$ & $12 \cdot 04$ & $13 \cdot 79$ & $11 \cdot 88$ & $13 \cdot 59$ \\
\hline
\end{tabular}

f In one case age was unspecified. 
TABLE IV

CORRELATION BETWEEN PERIOD OF AMENORRHOEA AND PARITY AND MATERNAL AGE

\begin{tabular}{|c|c|c|c|c|c|c|c|}
\hline \multirow{2}{*}{$\begin{array}{l}\text { Correlation } \\
\text { Between }\end{array}$} & \multirow{2}{*}{$\begin{array}{l}\text { Sex of } \\
\text { Child }\end{array}$} & \multirow{2}{*}{$\begin{array}{l}\text { Correlation } \\
\text { Coefficient }\end{array}$} & \multicolumn{5}{|c|}{ Correlation Coefficient Corrected for } \\
\hline & & & Maternal Age & Parity & Length of Cycle & $\begin{array}{c}\text { Age and } \\
\text { Length of Cycle }\end{array}$ & $\begin{array}{c}\text { Parity and } \\
\text { Length of Cycle }\end{array}$ \\
\hline \multirow{2}{*}{$\begin{array}{l}\text { Period of Amenorrhoea } \\
\text { and Parity }\end{array}$} & Male & $-0 \cdot 040$ & -0.029 & 一 & -0.031 & -0.030 & - \\
\hline & Female & -0.042 & -0.034 & - & -0.025 & -0.028 & - \\
\hline \multirow{2}{*}{$\begin{array}{l}\text { Period of Amenorrhoea } \\
\text { and Maternal Age }\end{array}$} & Male & -0.030 & - & -0.011 & -0.008 & - & +0.008 \\
\hline & Female & -0.025 & - & -0.002 & +0.002 & - & +0.016 \\
\hline
\end{tabular}

association. But the slight negative correlations would not be expected to be apparent from the means. An alternative method of enquiring whether the association of the period of amenorrhoea with age and parity is due to the interval preceding or following ovulation, is to examine the correlation between period of amenorrhoea and each of the variables, fixing length of cycle.

The correlations are given in Table IV. There are small negative correlations between period of amenorrhoea and parity (males, -0.040 ; females, -0.042 ), and between period of amenorrhoea and maternal age (males, -0.030 ; females, -0.025 ). The correlation with parity appears to be independent of both maternal age and length of cycle, for it is present when corrected for both these variables (males, -0.030 ; females, -0.028 ). But there is a slight positive correlation between the period of amenorrhoea and maternal age when parity and length of cycle are fixed (males, +0.008; females, $+0.016)$. The negative correlation between period of amenorrhoea and age before correction for length of cycle and parity appears to be due to:

(a) a negative association (males, -0.202 ; females, -0.159 ) between length of cycle and age, the period of amenorrhoea and length of cycle being positively correlated (males, +0.105; females, $+0 \cdot 167$ ) (b) a positive association between maternal age and parity (males, +0.489 ; females, +0.523 ), period of amenorrhoea and parity being negatively correlated (as noted above).

\section{SUMmary}

The period between ovulation and birth has been estimated for each of 763 women by:

(a) using information about mean length of cycle to estimate the interval between onset of menstruation and ovulation,

(b) subtracting this interval from the period of amenorrhoea.

It is shown that the period between ovulation and birth is somewhat less variable than the period of $\vec{v}$ amenorrhoea, percentages of deliveries during what $\omega$ corresponds to the 41 st week of amenorrhoea being 31.7 per cent. and 25.8 per cent. respectively. It also noted that a small negative correlation between period of amenorrhoea and parity is independent of both length of cycle and maternal age, but there is a very small positive correlation between period of amenorrhoea and maternal age when length of cycle and parity are held constant.

\section{REFERENCES}

Gunn, D. L., Jenkins, P. M., and Gunn, A. L. (1937). J. Obstet. Gynaec. Brit. Emp., 44, 839.

Karn, M. N., and Penrose, L. S. (1951). Ann. Eugen., Camb., 16,147. McKeown, T., Gibson, J. R., and Dougray, T. (1935). Brit. med. J., 2. 253. 